Jpn. J. Genet. (1987) 62, pp. 349-361

\title{
Hybrid dysgenesis in Drosophila melanogaster : a case of somatic effects including developmental retardation and the death in dysgenic females.
}

\author{
By Fuyuo HiHara \\ Biological Institute, Faculty of General Education, Ehime University, \\ Matsuyama, Ehime 790
}

(Received August 7, 1987)

\begin{abstract}
A case of somatic defect due to apparent P-M hybrid dysgenesis was found; developmental retardation and the death was observed in the hybrid females derived from crosses of $C$ (1) $D X$ (M type) females and males of the specific $\mathrm{P}$ lines. One of these $\mathrm{P}$ lines was $C y / P m$ maintained in our laboratory. The others were derived from crosses between ebony (M type) females and $C y / P m$ males, allowing the chance of transposition of $\mathrm{P}$ elements from the $C y$ to the ebony-derived chromosomes. The developmental retardation of hybrid females as measured by the sex ratio was positively correlated with GD sterility and $s n^{w}$ mutability. Hybrid females originated from the other $\mathrm{M} \times \mathrm{P}$ crosses did not shows such a somatic effect. The developmental retardation in dysgenic females appeared to proceed the larval and pupal stages, while GD sterility takes place during the embryonic stage. Female lethality as a result of developmental retardation increased proportional to increasing developmental temperature of dysgenic females. However, a critical threshold of temperature as known in GD sterility was not observed.
\end{abstract}

\section{INTRODUCTION}

P-M hybrid dysgenesis in Drosophila melanogaster shows several unusual traits in the germ line, including a high mutation rate, male recombination, chromosomal rearrangement and sterility (Kidwell et al., 1977). All of these traits are caused by $\mathrm{P}$ elements when introduced into an $\mathrm{M}$ cytotype egg (Engels, 1983). Among these traits, a developmental failure of the germ line, gonadal dysgenesis (GD) sterility, takes place when dysgenic hybrids are raised at high temperature, usually over $25^{\circ} \mathrm{C}$ (Kidwell and Novy, 1979).

GD sterility has two distinct characters which are different from the other dysgenic traits such as mutation, male recombination and chromosome rearrangement. One of them is that GD sterility is inducible at nearly 100 percent at high temperature, contrasting to the other traits which occur at a lower frequency even if males of a strongest $P$ strain were crossed to $M$ females. The other is that GD sterility takes place during the embryonic stages of dysgenic hybrids themselves. Simmons et al. (1984) examined dysgenesis- 
induced mutations at specific loci or in specific chromosome regions. The mutation rate was 0.4 percent at Beadex $(B x)$ locus which showed the highest mutation rate among the loci examined. Accordingly, the time between the introduction of the $\mathrm{P}$ type chromosomes into the $\mathrm{M}$ type cells and expression of GD sterility is too short to assume mutations that probably arose from the insertion of $\mathrm{P}$ elements into the loci related to the germ cell development. A mechanism responsible for GD sterility, thus, can not assume P-elementmediated mutation or chromosome rearrangements, although the cellular or subcellular basis of GD sterility is still unknown.

Although most of previous studies indicate that the dysgenic traits are limited to germ line cells, dysgenesis can actually occur in the premeiotic stages beside cells undergoing meiosis because, in most cases, the recovery of clusters of affected progeny has been observed (Sinclair and Grigliatti, 1985). This fact leads us to suppose that $P$ elements may also have some effects on somatic cells. However, several studies designed to detect somatic effects of $\mathrm{P}$ elements such as somatic mutations or somatic recombinations failed to obtain evidence of P-element-mediated dysgenesis in somatic cells (Thompson, Woodruff and Saefer, 1978; McElwain, 1986). Dysgenic traits employed in the previous studies of somatic effects were those which depend on somatic transposition of $\mathrm{P}$ elements.

This article reports a case of dysgenic trait expressed in somatic cells at a high frequency like GD sterility, which may not depend on $\mathrm{P}$ element transposition.

\section{MATERIALS AND METHODS}

\section{Strains}

M strains; these strains include ebony, $y s n^{w} / y^{+} \mathrm{Y} ; b w$; st and $C(1) D X, y f /$ $Y / y w n^{3} B$ (hereafter designated $\left.C(1) D X\right)$. The second strain has defective $\mathrm{P}$ elements incapable of transposing themselves and has an $\mathrm{M}$ cytotype. When females of this strain are mated to males carring a complete $P$, these defective $\mathrm{P}$ elements can be activated to yield the $s n^{+}$revertants or the more extreme mutants, $s n^{e}$ (Engels, 1984).

$\mathrm{P}$ strains; original $\mathrm{P}$ strain used in this article bears the second chromosome dominant markers; In $(2 L R) C y / \operatorname{In}(2 L R) b w^{v 1}$ (hereafter designated $\left.C y / P m\right)$ (Yamamoto, Hihara and Watanabe, 1984). The P lines used in most of the experiments, the H I, H II and H III series, were derived from crosses between ebony females and $C y / P m$ males. Male progenies heterozygous for $C y$ were backcrossed to ebony females for four generations to substitute the other $C y$-derived chromosomes to those of ebony. Then, heterozygous $C y$ females and males were inbred for a certain number of generations to let $\mathrm{P}$ elements to transpose from the $\mathrm{Cy}$ chromosome to the ebony chromosomes. 
Finally, the $C y$ chromosome was excluded from the genome (Hihara, Hisamatsu and Hirota, 1985). Another P strain, $\pi_{2}$, was used to test somatic effects of $\mathrm{P}$ elements (see Engels (1979) for a description of this stock).

\section{Test of GD sterility}

The ebony strain was used to detect GD sterility in M type. Crosses between ebony females and males under test which produce hybrid females were kept at $28^{\circ} \mathrm{C}$ throughout the experiments. The female flies emerged were allowed to develop their ovaries for about three days before dissected to see whether or not they have rudimentary ovaries. The frequency of GD sterility was measured as the percentage of the rudimentary ovaries.

\section{Test of sn wutability}

Males of a strain being tested the transposase activity were mated to $y$ $s n^{w}$; st females. Then, male progeny in which the germ line assumed to have had mutation of $s n^{w}$ to $s n^{e}$ or $s n^{+}$were mated to $C(1) D X, y f / Y$ (attached X) females to detect $s n^{w}$ mutation in the next male progeny. The mutation rate of $s n^{w}$ was calculated as the proportion of the $s n^{e}$ and $s n^{+}$mutants among the total flies scored. The temperature was maintained at $25^{\circ} \mathrm{C}$ throughout these experiments.

Test of female developmental retardation and death.

To assay somatic effects of $\mathrm{P}$ elements, $C$ (1) $D X, y f / Y$ females (M type) were crossed to males to be tested. Females were allowed to lay eggs for two days if not mentioned otherwise, and then these cultures were kept at $25^{\circ} \mathrm{C}$. Somatic effects were detected in two ways. First, for the test of female lethality, total female and male progeny from each cross were counted to see whether number of females were reduced or not. Second, the sex ratio of the emerging flies was scored at two days interval from 10 days after oviposition to detect developmental retardation in female progeny.

\section{RESULTS}

The female specific lethality as indicated by sex ratio in the hybrids from the $\mathrm{M} \times \mathrm{P}$ crosses is given in Table 1 . All the three cases which induced relatively high levels of female lethality involves $C(1) D X$ females as M type parent and $C y / P m$ or HI-3 and $\mathrm{HI}-4$ male parents.

The HI-3 and HI-4 lines of the flies used in this experiment were derived from hybrids between ebony $(\mathrm{M})$ females and $C y / P m(\mathrm{P})$ males; hybrid $C y$ males were backcrossed to ebony females for four generations and, thenafter, the $C y$ flies were inbred for a certain number of generations where cytotype might be changed from the $M$ to the $P$ type (Sved, 1987), allowing the chance 
Table 1. Sex ratio of the $F_{1}$ progeny emerged from various crosses for the P-M system (at $25^{\circ} \mathrm{C}$ )

\begin{tabular}{|c|c|c|c|c|c|c|}
\hline \multicolumn{2}{|c|}{ CROSS } & \multicolumn{3}{|c|}{ NUMBER OF PROGENY } & \multirow{2}{*}{$\begin{array}{l}\text { SEX RATIO } \\
=\text { Female/Total }\end{array}$} & \multirow{2}{*}{$\begin{array}{c}\text { PM } \\
\text { SYSTEM } \\
\text { CROSS }\end{array}$} \\
\hline Female & Male & Female & Male & Total & & \\
\hline \multicolumn{2}{|c|}{$\mathrm{C}(1) \mathrm{DX} \times \mathrm{C}(1) \mathrm{DX}$} & 892 & 953 & 1845 & 0.4835 & $\mathrm{M} \times \mathrm{M}$ \\
\hline $\mathrm{H} \mathrm{I}-3 \times$ & $\times \mathrm{H} \mathrm{I}-3$ & 1452 & 1551 & 3003 & 0.4835 & $\mathrm{P} \times \mathrm{P}$ \\
\hline \multicolumn{2}{|c|}{$\mathrm{C}(1) \mathrm{DX} \times \mathrm{H} \mathrm{I}-3$} & 367 & 1300 & 1667 & $0.2202^{* *}$ & $\mathrm{M} \times \mathrm{P}$ \\
\hline \multicolumn{2}{|c|}{$\begin{array}{l}\text { C (1) DX } \times \text { H I-3 } \\
\text { H I-3 } \times \text { C (1) DX }\end{array}$} & 348 & 351 & 699 & 0.4979 & $\mathrm{P} \times \mathrm{M}$ \\
\hline \multicolumn{2}{|c|}{ C (1) DX $\times$ H I-4 } & 1093 & 1687 & 2780 & $0.3932 * *$ & $\mathrm{M} \times \mathrm{P}$ \\
\hline \multicolumn{2}{|c|}{$\mathrm{C}(1) \mathrm{DX} \times C y / P m$} & 338 & 558 & 896 & $0.3772^{* *}$ & $\mathrm{M} \times \mathrm{P}$ \\
\hline \multicolumn{2}{|c|}{$\mathrm{C}(1) \mathrm{DX} \times \pi_{2}$} & 527 & 539 & 1066 & 0.4944 & $\mathrm{M} \times \mathrm{P}$ \\
\hline \multicolumn{2}{|c|}{$\mathrm{C}(1) \mathrm{DX} \times$ ebony } & 601 & 617 & 1218 & 0.4934 & $\mathrm{M} \times \mathrm{M}$ \\
\hline ebony $>$ & $\times C y / P m$ & 488 & 496 & 984 & 0.4959 & $\mathrm{M} \times \mathrm{P}$ \\
\hline ebony & $\times \mathrm{C}(1) \mathrm{DX}$ & 529 & 588 & 1117 & 0.4736 & $\mathrm{M} \times \mathrm{M}$ \\
\hline ebony & $\times \mathrm{H} \mathrm{I}-3$ & 577 & 602 & 1179 & 0.4894 & $\mathrm{M} \times \mathrm{P}$ \\
\hline ebony & $\times \mathrm{H} \mathrm{I}-4$ & 660 & 679 & 1339 & 0.4929 & $\mathrm{M} \times \mathrm{P}$ \\
\hline
\end{tabular}

** significantly different from 0.5 at the $1 \%$ level.

of $\mathrm{P}$ element transposition from the $C y$ chromosome to the ebony-derived chromosomes. Finally, the $C y$ chromosomes were removed from the lines (Hihara, Hisamatsu and Hirota, 1985).

The absence of pronounced female lethality was found in four different types of the crosses. First, inbreeding of the $C(1) D X(\mathrm{M})$ strain or the H I-3 (P) line induced no female lethality. Second, progeny from the crosses between $\mathrm{P}$ type female and $\mathrm{M}$ type male also showed no female lethality. Third, $\pi_{2}$ males, a strong $\mathrm{P}$ strain, did not yield any lethality in their daughters. Fourth, ebony females, a typical M strain, were not capable of inducing female lethality even if HI-3 males were used as their partners.

The female specific lethality detected in the hybrids, therefore, reflects the contribution of $\mathrm{P}$ elements introduced into $\mathrm{M}$ cytotype cells. This phenomenon, however, was expressed in the restricted crosses which involve $C(1)$ $D X$ females and males with $\mathrm{P}$ elements derived from the original $C y / P m$ stock.

To ascertain the female specific lethality to be caused by $\mathrm{P}$ elements, the relationships between GD sterility, $s n^{w}$ mutability and female lethality were examined (Table 2). In the $\mathrm{H}$ I series used in this experiment, the $C y$ chromosomes were removed after coexsistence with the ebony-derived chrosomes for 10 generations.

The frequency of GD sterility was relatively high in 5 out of 8 lines tested, especially, in HI-3 and HI-4. The other 3 lines did not induce substantial frequency of GD sterility; these lines, therefore, appeared not to have $\mathrm{P}$ activity. 
Table 2. Relationships between frequency of GD sterility, $s n^{w}$ mutation rate and sex ratio in $F_{1}$ hybrid of the $H I$ lines.

\begin{tabular}{|c|c|c|c|c|c|c|c|c|c|c|c|c|c|c|}
\hline \multirow{2}{*}{\multicolumn{2}{|c|}{ Line }} & \multicolumn{5}{|c|}{ GD sterility } & \multicolumn{5}{|c|}{$s n^{w}$ mutation } & \multicolumn{3}{|c|}{ Sex ratio } \\
\hline & & 2 & 1 & 0 & $\mathrm{~T}$ & $\% \mathrm{~s}$ & $s n^{w}$ & $s n^{+}$ & $s n^{e}$ & $\mathrm{~T}$ & $\%$ & F & M & S.R \\
\hline $\mathrm{H}$ & $\mathrm{I}-1$ & 359 & 9 & 0 & 368 & 1.2 & 741 & 50 & 33 & 824 & 1.2 & 418 & 420 & 0.4988 \\
\hline $\mathrm{H}$ & I -2 & 127 & 114 & 131 & 372 & 50.8 & 425 & 201 & 95 & 721 & 41.1 & 528 & 610 & $0.4640^{*}$ \\
\hline $\mathrm{H}$ & $I-3$ & 3 & 32 & 350 & 385 & 95.1 & 287 & 175 & 172 & 634 & 54.7 & 116 & 584 & $0.1657^{* *}$ \\
\hline $\mathrm{H}$ & I -4 & 10 & 28 & 322 & 360 & 93.3 & 295 & 131 & 198 & 624 & 52.7 & 642 & 725 & $0.4696 * *$ \\
\hline $\mathrm{H}$ & $I-5$ & 189 & 133 & 51 & 373 & 31.5 & 608 & 47 & 34 & 689 & 11.7 & 563 & 642 & $0.4672^{* *}$ \\
\hline $\mathrm{H}$ & I -6 & 325 & 7 & 2 & 334 & 1.6 & 742 & 137 & 44 & 923 & 19.6 & 529 & 539 & 0.4953 \\
\hline $\mathrm{H}$ & I -7 & 269 & 8 & 7 & 284 & 3.9 & 612 & 70 & 66 & 748 & 18.2 & 856 & 853 & 0.5009 \\
\hline $\mathrm{H}$ & I -8 & 76 & 122 & 75 & 273 & 49.8 & 503 & 109 & 67 & 679 & 26.0 & 876 & 948 & 0.4803 \\
\hline
\end{tabular}

** significantly different from 0.5 at the $1 \%$ level.

* significantly diffegent from 0.5 at the $5 \%$ level.

The mutation rate of $s n^{w}$, the frequency of $s n^{+}$and $s n^{e}$ among the total flies, was high in all but one line, H I-1. Three lines, H I-2, H I-3 and H I-4, could destabilize $s n^{w}$ in hybrid males with high frequencies. Two lines that did not induce GD sterility had significant level of $s n^{w}$ mutation, demonstrating that these two traits can be uncoupled. Spearman's rank correlation coefficient between the abilities to induce GD sterility and to destabilize $s n^{w}$ was $r=0.98$ $(\mathrm{P}<0.01)$ for the data given in Table 2 , showing a highly positive correlation.

Significant distortion of the sex ratio from the theoretical value of 0.5 was found in hybrid progeny of four lines, from H I-2 to H I-5. Among them, H I-3 line induced a high level of sex ratio distortion; the female progeny ratio were greatly reduced than the theoretical frequency of 50\%. Spearman's rank correlation coefficients are $r=0.81(\mathrm{P}<0.05)$ between the abilities to induce GD sterility and to cause sex ratio distortion, and $r=0.67 \quad(\mathrm{P}<0.05)$ between the abilities to destabilize $s n^{w}$ and to cause sex ratio distortion.

Although there are exceptional cases, sex ratio distortion had approximately linear relationships with two well known dysgenic characters, GD sterility and $s n^{w}$ mutability. Thus, female specific lethality observed in the present study can be regarded as a dysgenic trait caused by $\mathrm{P}$ elements.

Other lines derived from the crosses between ebony females and $C y / P m$ males were tested for the ability to induce three dysgenic traits like in the case of the HI series (Table 3).

In the $\mathrm{H}$ II series, all of the lines had very low ability to induce GD sterility and no ability to induce $s n^{w}$ mutation. These facts suggest that the H II series has no or very low $\mathrm{P}$ activity. Also, female lethality indicated by sex ratio was very low in all but one line, H II-7.

The H III series also induced little or no GD sterility. All but one line of the H III series did not destabilize $s n^{w}$; the single exception was H III-2 line 
Table 3. Relationship between frequency of GD sterility, sn wutation rate and sex ratio in $F_{1}$ hybrid of the $H$ II, III lines.

\begin{tabular}{|c|c|c|c|c|c|c|c|c|c|c|c|c|c|}
\hline \multirow{2}{*}{ Line } & \multicolumn{5}{|c|}{ GD sterility } & \multicolumn{5}{|c|}{$s n^{w}$ mutation } & \multicolumn{3}{|c|}{ Sex ratio } \\
\hline & 2 & 1 & 0 & $\mathrm{~T}$ & $\% \mathrm{~S}$ & $s n^{w}$ & $s n^{+}$ & $s n^{e}$ & $\mathrm{~T}$ & $\%$ & $\mathrm{~F}$ & M & S.R \\
\hline H II -1 & 321 & 17 & 1 & 339 & 2.8 & 1280 & 0 & 0 & 1280 & 0.0 & 108 & 137 & 0.4408 \\
\hline $\mathrm{H} \quad \mathrm{II}-2$ & 320 & 11 & 3 & 334 & 2.5 & 1189 & 0 & 0 & 1189 & 0.0 & 177 & 190 & 0.4823 \\
\hline H II -3 & 324 & 13 & 3 & 340 & 2.8 & 1470 & 0 & 0 & 1470 & 0.0 & 169 & 182 & 0.4815 \\
\hline $\mathrm{H} \quad \mathrm{II}-4$ & 298 & 7 & 1 & 306 & 1.5 & 767 & 0 & 0 & 767 & 0.0 & 187 & 216 & 0.4640 \\
\hline H II -5 & 287 & 10 & 0 & 297 & 1.7 & 711 & 0 & 0 & 711 & 0.0 & 161 & 147 & 0.5227 \\
\hline $\mathrm{H} \quad \mathrm{II}-6$ & 340 & 15 & 2 & 357 & 2.7 & 649 & 0 & 0 & 649 & 0.0 & 141 & 149 & 0.4862 \\
\hline $\mathrm{H} \quad \mathrm{II}-7$ & 283 & 10 & 2 & 295 & 2.4 & 585 & 0 & 0 & 585 & 0.0 & 164 & 225 & $0.4216^{* *}$ \\
\hline $\mathrm{H}$ II -8 & 306 & 9 & 1 & 316 & 1.7 & 1004 & 0 & 0 & 1004 & 0.0 & 204 & 245 & 0.4543 \\
\hline H III-1 & 90 & 2 & 2 & 94 & 3.2 & 1456 & 0 & 0 & 1456 & 0.0 & 186 & 216 & 0.4627 \\
\hline H III-2 & 128 & 1 & 1 & 130 & 1.2 & 1251 & 60 & 27 & 1338 & 6.5 & 838 & 1228 & $0.4056^{* *}$ \\
\hline H III-3 & 153 & 1 & 1 & 155 & 1.0 & 1053 & 0 & 0 & 1053 & 0.0 & 127 & 204 & $0.3837 * *$ \\
\hline H III-4 & 152 & 3 & 1 & 155 & 1.6 & 1296 & 0 & 0 & 1296 & 0.0 & 134 & 179 & $0.4281 *$ \\
\hline H III-5 & 203 & 2 & 1 & 206 & 1.0 & 1362 & 0 & 0 & 1368 & 0.4 & 106 & 174 & $0.3786 * *$ \\
\hline H III-6 & 171 & 1 & 0 & 172 & 0.3 & 1401 & 0 & 0 & 1401 & 0.0 & 154 & 171 & 0.4738 \\
\hline H III-7 & 160 & 0 & 0 & 160 & 0.0 & 803 & 0 & 0 & 803 & 0.0 & 137 & 217 & $0.3870^{* *}$ \\
\hline
\end{tabular}

** significantly different from 0.5 at the $1 \%$ level.

$*$ significantly different from 0.5 at the $5 \%$ level.

which showed a relatively low frequency of the mutation and, therefore, had similar properties as $\mathrm{H} \mathrm{I}-6$ and $\mathrm{H} \mathrm{I}-7$ lines.

In this series, female lethality was observed in 5 out of 7 lines tested. Thus, the H III series had properties quite different from those of the H II series and demonstrated that female lethality could be uncoupled with the other two dysgenic traits. In addition, $\mathrm{H}$ III-2, 4, 6 lines had cytotype which was capable of suppressing GD sterility. However, none of the other H III lines showed any ability of suppressing GD sterility. This indicates that the ability of inducing developmental retardation is also uncoupled with that of determining the cytotype.

The results presented in Tables 1, 2 and 3 strongly indicate that female lethality observed here is caused by $\mathrm{P}$ elements. However, this trait is not always coupled with the others, suggesting that a different type of $\mathrm{P}$ elements might be involved in this phenomenon. A mutant $\mathrm{P}$ element, $P\{r y(\Delta 2-3)\}$, is known to induce somatic excision of a nonautonomous $\mathrm{P}$ element (Laski, Rio and Rubin 1986). An assay for the ability of $\mathrm{P}$ element-mediated somatic excision of the H I-3 line was carried out by crossing $y s n^{w}$; $b w$; st females to H I-3 males. About 1200 male progeny from that cross, however, produced no somatic mosaics at all, having only $s n^{w}$ bristles (data not shown). 


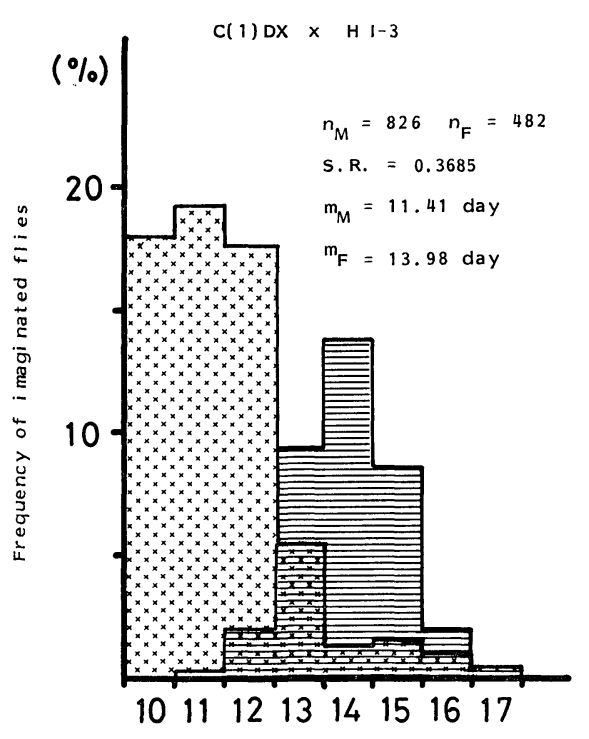

Day after oviposition

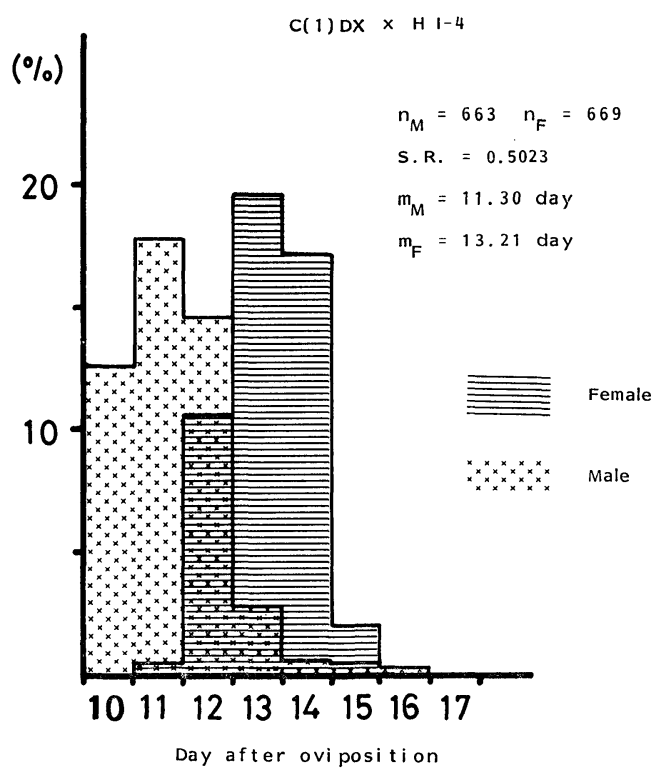

Fig. 1. Relative developmental rate which was examined by scoring the time of emergence of male and female progenies from crosses, $C(1) D X \times \mathrm{H} \mathrm{I-3} \mathrm{(left)} \mathrm{and}$ $C$ (1) $D X \times \mathrm{H} \mathrm{I-4} \mathrm{(right).} n_{M}, n_{F}$; number of males and females examined, S. R.; proportion of females among total flies, $m_{M}, m_{F}$; mean developmental time of males and females.

In Tables 1-3, the somatic effects of dysgenesis was assessed by female lethality measured by distortion of sex ratio from the theoretical value of 0.5 . Female lethality, however, was thought to be an extreme case of developmental retardation in females. Therefore, relative developmental rate between sexes might be more pertinent to the matter in hand.

Figure 1 shows developmental time of male and female progeny. Mean developmental time of both sexes $m_{M}$ and $m_{F}$, are not absolute value because $C$ (1) $D X$ females mated were allowed oviposition for two days and, furthermore, the male flies appeared in the 9 th day after oviposition were added to those emerged in the 10 th day.

In both crosses, development of hybrid females was conspiciously delayed for about 2 days compared to hybrid males of which developmental rate was regarded to be normal. In progeny of $\mathrm{H} \mathrm{I}-3$ males which induced high frequency of the female lethality, developmental retardation of females was much larger than that of H I-4 progeny. One possible cause for the female lethality is, thus, the developmental delay of female progeny. As seen in the case of H I-4 progeny, the female lethality was insignificant when the development of female progeny was not delayed compared to the normal time schedule. 
Table 4. Number of fies emerged and sex ratio counted for two days interval in $F_{1}$ hybrids from various crosses.

\begin{tabular}{|c|c|c|c|c|c|c|c|c|c|}
\hline Cross & \multicolumn{9}{|c|}{ Number of flies emerged ( 2 days interval) and sex ratio } \\
\hline \multirow{2}{*}{ Female } & & 1 & 2 & 3 & \multicolumn{2}{|c|}{4} & \multicolumn{2}{|l|}{5} & \multirow{2}{*}{$F^{\mathrm{T}}$} \\
\hline & & $\mathrm{M}$ & M & M & $\mathrm{F}$ & $\mathrm{M}$ & $\mathrm{F}$ & M & \\
\hline \multirow[t]{2}{*}{$\mathrm{C}(1) \mathrm{DX} \times \pi_{2}$} & $\mathrm{n}$ & $221 \quad 209$ & $198 \quad 228$ & 96 & 12 & 11 & 0 & 0 & 527 \\
\hline & S.R. & 0.5140 & 0.4648 & 0.5134 & \multicolumn{2}{|c|}{0.5297} & - & & 0.4944 \\
\hline \multirow[t]{2}{*}{$\mathrm{H} \quad \mathrm{I}-3$} & $\mathrm{n}$ & 10194 & $232 \quad 226$ & $15 \quad 31$ & 0 & 0 & - & - & $348 \quad 351$ \\
\hline & S.R. & 0.5179 & 0.5066 & 0.3261 & - & & - & & 0.4979 \\
\hline \multirow[t]{2}{*}{$\mathrm{H}$ III-2 $\times \mathrm{C}(1) \mathrm{DX}$} & $\mathrm{n}$ & $50 \quad 27$ & $63 \quad 66$ & $64 \quad 74$ & 16 & 19 & 0 & 0 & $193 \quad 191$ \\
\hline & S.R. & 0.6494 & 0.4884 & 0.4476 & \multicolumn{2}{|c|}{0.4576} & - & & 0.5026 \\
\hline \multirow[t]{2}{*}{$\mathrm{C}(1) \mathrm{DX} \times \mathrm{H} \quad \mathrm{II}-3$} & $\mathrm{n}$ & $35 \quad 115$ & $104 \quad 60$ & $30 \quad 7$ & 0 & 0 & - & - & $169 \quad 182$ \\
\hline & S.R. & 0.2333 & 0.6341 & 0.8108 & - & & - & & 0.4815 \\
\hline \multirow[t]{2}{*}{$\mathrm{C}(1) \mathrm{DX} \times \mathrm{H} \quad$ II -6} & $\mathrm{n}$ & $34 \quad 83$ & $83 \quad 56$ & $24 \quad 10$ & 0 & 0 & - & - & $141 \quad 149$ \\
\hline & S.R. & 0.2906 & 0.5971 & 0.7059 & - & & - & & 0.4862 \\
\hline $\mathrm{C}(1) \mathrm{DX} \times C y / P m$ & $\mathrm{n}$ & $9 \quad 175$ & $126 \quad 252$ & $150 \quad 116$ & 53 & 15 & 0 & 0 & $338 \quad 558$ \\
\hline & S.R. & 0.0489 & 0.3333 & 0.5639 & 0.7 & & - & & 0.3772 \\
\hline $\mathrm{C}(1) \mathrm{DX} \times \mathrm{H} \quad \mathrm{III}-2$ & $\mathrm{n}$ & 1445 & $144 \quad 320$ & $375 \quad 419$ & 226 & 42 & 52 & 2 & $838 \quad 1228$ \\
\hline & S.R. & 0.0022 & 0.3103 & 0.4723 & 0.8 & & 0.9630 & & 0.3878 \\
\hline
\end{tabular}

Many progeny from $C(1) D X \times \mathrm{H} \mathrm{I-3}$ cross, died at the pupal stage. In the pupa, the adult head and thorax are completely formed. However, the abdominal segments are remained undifferentiated to the adult epidermis. Thus, the lethality of hybrid females is due to developmental arrest at the stage of the "pharate adult". Many of emerged females from $C(1) D X \times \mathrm{H} \mathrm{I}-3$ cross had the abnormal abdomen; the sternites or tergites were irregularly formed or sometimes completely lost. In $\mathrm{H} \mathrm{I}-4$ cross, the death of the "pharate adult" was much reduced, but morphological abnormality of the adult abdomen was also found in many females.

Some of the crosses other than the above experiment were carried out to see whether or not developmental retardation of hybrid females could be generally induced among $\mathrm{M} \times \mathrm{P}$ crosses (Table 4). The emerging flies were scored at two days interval from the 10 th day after the oviposition. In $C(1)$ $D X \times \pi_{2}, \mathrm{H}$ I- $3 \times C(1) D X$ and $\mathrm{H}$ III- $2 \times C$ (1) $D X$ crosses, obvious sex ratio change was not observed throughout the emerging period. In contrast with this, four $\mathrm{M} \times \mathrm{P}$ crosses showed reduced number of hybrid females in the earlier counts irrespective of the final sex ratio; two male lines, H II-3 and H II-6, which did not express the sex ratio distortion in total induced female reduction in ealier days. However, the extent of the developmental retardation in these crosses was smaller than the two crosses, $C$ (1) $D X \times C y / P m$ and $C$ (1) $D X \times \mathrm{H}$ III-2, which showed obvious distortion of the final sex ratio due to female lethality. Results presented in Figure 1 and Table 4 provide some indication 
Table 5. Comparison of sex ratio between two different stages of development at various times after oviposition.

\begin{tabular}{|c|c|c|c|c|c|}
\hline $\begin{array}{l}\text { Time after } \\
\text { oviposition }\end{array}$ & $\begin{array}{l}\text { Developmental } \\
\text { stage }\end{array}$ & Female & Male & Total & Sex ratio \\
\hline \multirow{2}{*}{$26 \mathrm{hr}$} & Egg & 76 & 67 & 143 & 0.5316 \\
\hline & 1st Inst. Larva & 82 & 74 & 156 & 0.5256 \\
\hline \multirow{2}{*}{$50 \mathrm{hr}$} & 1st Inst. Larva & 54 & 22 & 76 & 0.7105 \\
\hline & 2nd Inst. Larva & 28 & 76 & 104 & 0.2692 \\
\hline \multirow{2}{*}{$\begin{array}{l}5 \text { day } \\
8 \mathrm{hr}\end{array}$} & $\{$ 3rd Inst. Larva & 298 & 34 & 332 & 0.8976 \\
\hline & Pupa & 15 & 333 & 348 & 0.0431 \\
\hline 17 day & Adult & 353 & 346 & 699 & 0.5050 \\
\hline
\end{tabular}

that sex ratio change during the emerging period may reflect better the $\mathrm{P}$ element activity than the final sex ratio.

To determine the time at which the developmental retardation of hybrid females occures, the sex ratio was checked at various times after oviposition (Table 5). The productivity of $C$ (1) $D X$ females was too low to obtain sufficient number of eggs in a short time period. $C(1) D X$ females mated with $\mathrm{H}$ I-4 males, therefore, were allowed to lay eggs for $6 \mathrm{hrs}$. If disparity in development at a certain time after the end of eviposition among individuals were caused by the time difference of oviposition, sex ratio may be expected to be equal between groups with more advanced and late stages. However, if developmental disparity were caused by female specific developmental retardation, the group showing an advanced stage may contain more male individuals than females and vice versa.

Results presented in Table 5 suggest that there is no difference of development between sexes during embryonic stages, because sex ratio was nearly equal between the first instar larvae and the unhatched eggs at $26 \mathrm{hr}$ after the oviposition. At $50 \mathrm{hr}$ after the oviposition, however, the presumed second instar larvae showed obviously reduced number of females, while the presumed first instar larvae contained increased number of females, suggesting that developmental retardation of hybrid females occured at least by this time. The distinction of the instar, in this case, was only tentative; the larvae were divided into two groups according to the body size, because identification of the instar using morphological characters, such as the mouth hooks or the larval spiracles was difficult. The larger group was supposed to contain the second instar larvae predominantly.

At 5 days $8 \mathrm{hr}$ after the oviposition, sex ratio distortion between the two groups, the third instar larva and pupa, seemed to be more remarkable than that of $50 \mathrm{hr}$ individuals. Thus, developmental retardation of hybrid females appears to proceed the larval stages. On the 17 th day after the oviposition, the sex ratio of the adult flies was nearly 0.5 as shown in Figure 1. 
Table 6. Reciprocal cross effect on sex ratio.

\begin{tabular}{|c|c|c|c|c|c|}
\hline \multicolumn{2}{|l|}{ Cross } & \multicolumn{3}{|c|}{ Number of progeny } & \multirow{2}{*}{$\begin{aligned} & \text { Sex ratio } \\
= & \text { female/total }\end{aligned}$} \\
\hline Female & Male & Female & Male & Total & \\
\hline $\mathrm{C}(1) \mathrm{DX}$ & $\times \mathrm{H} \quad \mathrm{I}-3$ & 367 & 1300 & 1667 & 0.2202 \\
\hline ebony & $\times \mathrm{H} \quad \mathrm{I}-3$ & 577 & 602 & 1179 & 0.4894 \\
\hline \multicolumn{2}{|c|}{ (C (1) DX $\times$ ebony $) \times \mathrm{H} \quad$ I -3} & 555 & 1966 & 2521 & 0.2202 \\
\hline \multicolumn{2}{|c|}{$($ ebony $\times \mathrm{C}(1) \mathrm{DX} \times \mathrm{H} \quad \mathrm{I}-3$} & 5111 & 5093 & 10204 & 0.5009 \\
\hline
\end{tabular}

Table 7. Effect of developmental temperature on sex ratio of the progeny of cross, $C$ (1) DX females $\times H I-3$ males.

\begin{tabular}{|c|c|c|c|c|c|}
\hline \multirow{2}{*}{$\begin{array}{l}\text { Day after } \\
\text { oviposition }\end{array}$} & \multicolumn{5}{|c|}{ Developmental temperature } \\
\hline & $18^{\circ} \mathrm{C}$ & $21^{\circ} \mathrm{C}$ & $24^{\circ} \mathrm{C}$ & $27^{\circ} \mathrm{C}$ & $30^{\circ} \mathrm{C}$ \\
\hline 10 & - & - & $\begin{array}{l}0.000 \\
(133)\end{array}$ & $\begin{array}{l}0.073 \\
(260)\end{array}$ & $\begin{array}{l}0.189 \\
(264)\end{array}$ \\
\hline 12 & - & - & $\begin{array}{l}0.000 \\
(67)\end{array}$ & $\begin{array}{l}0.130 \\
(115)\end{array}$ & $\begin{array}{l}0.333 \\
(66)\end{array}$ \\
\hline 14 & - & $\begin{array}{l}0.000 \\
\text { (198) }\end{array}$ & $\begin{array}{l}0.194 \\
(237)\end{array}$ & $\begin{array}{l}0.207 \\
(188)\end{array}$ & $\begin{array}{l}0.600 \\
(60)\end{array}$ \\
\hline 16 & - & $\begin{array}{l}0.222 \\
(198)\end{array}$ & $\begin{array}{l}0.271 \\
(166)\end{array}$ & $\begin{array}{l}0.103 \\
(97)\end{array}$ & $\begin{array}{c}0.750 \\
\left(\begin{array}{l}4 \\
)\end{array}\right.\end{array}$ \\
\hline 18 & $\begin{array}{l}0.016 \\
\text { (184) }\end{array}$ & $\begin{array}{l}0.339 \\
\text { (127) }\end{array}$ & $\begin{array}{l}0.435 \\
(85)\end{array}$ & $\begin{array}{l}0.150 \\
(60)\end{array}$ & - \\
\hline 20 & $\begin{array}{c}0.333 \\
\text { (186) }\end{array}$ & $\begin{array}{l}0.556 \\
(133)\end{array}$ & $\begin{array}{l}0.260 \\
(96)\end{array}$ & $\begin{array}{l}0.077 \\
(13)\end{array}$ & - \\
\hline 22 & $\begin{array}{l}0.500 \\
(154)\end{array}$ & $\begin{array}{l}0.635 \\
(96)\end{array}$ & $\begin{array}{l}0.385 \\
(13)\end{array}$ & - & - \\
\hline 24 & $\begin{array}{l}0.970 \\
(101)\end{array}$ & $\begin{array}{l}0.714 \\
(14)\end{array}$ & - & - & - \\
\hline $\begin{array}{c}\text { mean } \\
\text { sex ratio }\end{array}$ & 0.384 & 0.303 & 0.198 & 0.127 & 0.282 \\
\hline
\end{tabular}

Developmental retardation of hybrid females manifests only when $M$ type $C(1) D X$ females were used as a parent. Does this imply that the $C$ (1) $D X$ strain has a special kind of $\mathrm{M}$ cytotype? Hybrid females were obtained from the cross, $C$ (1) $D X \times e b o n y$, and its reciprocal cross. Results represented in Table 6 indicate that effects of the reciprocal cross might be caused by the difference of cytotype. But, in this mating scheme, another factor to be considered, chromosomal contribution, could not be separated from the cytotype difference; the sex chromosome constitution of hybrid females from $C$ (1) $D X$ $X$ ebony cross is XXY, while females from its reciprocal cross is XX. Since $C$ (1) $D X$ strain has a typical M cytotype in regard to GD sterility, there is a reason to believe that the observed reciprocal cross effects may be attributed to the sex chromosome constitution rather than the cytotype difference. 
Temperature sensitivity test of developmental retardation of hybrid females from $C$ (1) $D X \times \mathrm{H} \mathrm{I-3}$ cross was performed at five different developmental temperatures ranging 18 to $30^{\circ} \mathrm{C}$ (Table 7). Developmental retardation was observed in every developmental temperatures; the sex ratio values increased with the lapse of the day after the oviposition. The total sex ratio value was decreased as the developmental temperature increased, though, at highest temperature, $30^{\circ} \mathrm{C}$, it increased again.

Thus, temperature sensitivity of sex ratio distortion has a similar tendency to that of male recombination rather than that of GD sterility.

\section{DISCUSSION}

Developmental retardation and partial death of hybrid females presented here may be caused by $\mathrm{P}$ elements. Evidences supporting this conclusion are, (1) inbreeding each of $\mathrm{P}$ or $\mathrm{M}$ strains did not manifest this trait, (2) crosses between $\mathrm{M}$ females and $\mathrm{P}$ males manifested this trait but not in these reciprocal crosses, and (3) the ability to induce this trait was positively correlated with the well known dysgenic traits, GD sterility and $s n^{w}$ mutability.

This trait, however, showed two features different from the other dysgenic traits. First, only a limited combinations of the $\mathrm{M}$ and $\mathrm{P}$ strains can induce this trait. Second, this trait is occurring in somatic cells of hybrid females. These two unusual features may be related to each other.

In some of the lines used here, $\mathrm{P}$ elements which cause developmental defect in hybrid females can be transposed from the $C y$ chromosome in the presence of the $\mathrm{P}$ elements which have the transposase activity.

$\mathrm{P}$ elements polymorphism in the molecular size and function were reported by O'Hare and Rubin (1983), Todo et al. (1984), Hihara et al. (1985) and Simmons and Bucholz (1985). All of these variable $\mathrm{P}$ elements may bear the $\mathrm{P}$ activity or $P$ cytotype that is observable experimentally.

Engels (1984) and Kour, Drier and Simmons (1986) found that there was a highly positive correlation between the ability to induce GD sterility and the ability to destabilize $s n^{w}$. However, they also found exceptional strains which had properties opposite to each other; one strain had a stronger ability to cause $s n^{w}$ destabilization than that of GD sterility, and the other strain had exactly the reverted situation. Such exceptional strains may have the cluster of P elements with one kind of function. Similarly, Kidwell (1984) found one strain which had rather strong ability to induce GD sterility than the amount of embryonic lethal (EL) sterility.

Most of previous evidences indicate that expression of hybrid dysgenesis is related to germ line cells (Thompson, Woodruff and Saefer, 1978; Colgan, 1982 ; Bingham, Kidwell and Rubin, 1982 ; Engels 1983). More recently, McElwain (1986) investigated de novo mutation or mitotic recombination in 
somatic cells due to P-M hybrid dysgensis. However, no significant increase was found in the frequency, size distribution of the mutant or recombinant somatic clones correlated to hybrid dysgenesis.

Laski, Rio and Rubin (1986) found that the existence of the third intron of $\mathrm{P}$ element was the sole basis for the germ line restricted activity of $\mathrm{P}$ element. They demonstrated that when $P\{r y(\Delta 2,3)\}$ males in which the proposed intron was precisely deleted were crossed to $s n^{w}$ females, greater than $90 \%$ of $r y^{+}$ male progeny were somatic mosaics, having a mixture of $s n^{w}, s n^{+}$and $s n^{e}$ bristles on the same individual and indicating somatic mutations.

Developmental retardation and death in hybrid females reported here is apparently one of somatic effects of hybrid dysgenesis because developmental temperature of the hybrid itself affects the frequency of dysgenic females and its expression is sex specific.

Results presented here will provide a new set of data relevant to the molecular structure of $\mathrm{P}$ element which has neither the transposase activity nor the ability to determine the cytotype but has the ability to induce somatic defects.

\section{REFERENCES}

Bingham‘ P. M., Kidwell, M. G. and Rubin, G. M. (1982) The molecular basis of P-M hybrid dysgenesis: the role of the $\mathrm{P}$ element, a $\mathrm{P}$-strain-specific transposon family. Cell 29, 9951004.

ColgAN, D· J. (1982) Somatic effects of hybrid dysgenesis in Drosophila melanogaster. Heredity 49, 243-246.

ENGELs, W. R. (1979) Extrachromosomal control of mutability in Drosophila melanogaster. Proc. Natl. Acad. Sci. USA 76. 4011-4015.

Engels, W. R. (1983) The P family of transposable elements in Drosophila. Ann. Rev. Genet. 17, 315-344.

ENGELS, W. R. (1984) A trans-acting product needed for P factor transposition in Drosophila. Science 226, 1194-1196.

Hihara, F., Hisamatsu, N. and Hirota, T. (1985) Hybrid dysgenesis in Drosophila melanogaster: Type conversions observed in the recently established isofemale lines and hybrid lines originated from $\mathrm{M} \times \mathrm{P}$ crosses. Jpn. J. Genet. 60, 199-214.

KIDWELL, M. G. (1984) Hybrid dysgenesis in Drosophila melanogaster: partial sterility associated with embryo lethality in the P-M system. Genet. Res. Camb. 44, 11-28.

Kidwell, M. G., Kidwell, J. F. and Sved, J. A. (1977) Hybrid dysgenesis in Drosophila melanogaster: a syndrome of aberrant traits including mutation, sterility and male recombination. Genetics 86, 813-833.

KIDwell, M. G. and Novy, J. B. (1979) Hybrid dysgenesis in Drosophila melanogaster: sterility resulting from gonadal dysgenesis in the P-M system. Genetics 92, 1127-1140.

Kocur, G. T., Drier, E. A. and Simmons, M. T. (1986) Sterility and hypermutability in the P-M system of hybrid dysgenesis in Drosophila melanogaster. Genetics 114, 1147-1163.

LAski, F. A., Rio, D. C. and Rubin, G. M. (1986) Tissue specificity of Drosophila P element transposition is regulated at the level of mRNA splicing. Cell 44, 7-19.

McElwaIN, M. K. (1986) The absence of somatic effects of P-M hybrid dysgenesis in Drosophila melanogaster. Genetics 113, 897-918.

O'Hare, K. and Rubin, G. M. (1983) Structure of P transposable elements and their sites of insertion and excision in the Drosophila melanogaster genome. Cell 34, 25-35. 
Simmons, M. J., Raymond, J. D., Johnson, N. A. and Fahey, T. M. (1984) A comparison of mutation rates for specific loci and chromosome regions in dysgenic hybrid males of Drosophila melanogaster. Genetics 106, 85-94.

Simmons, M. J. and Bucholz, L. M. (1985) Transposase titration in Drosophila melanogaster: A model of cytotype in the P-M system of hybrid dysgenesis. Proc. Natl. Acad. Sci. USA 82, 8119-8123.

Sinclair, D. A. R. and Grigliatti, T. A. (1985) Investigations of the nature of P-induced male recombination in Drosophila melanogaster. Genetics 110, 257-279.

Sved, J. A. (1987) Hybrid dysgenesis in Drosophila melanogaster: evidence from sterility and southern hybridization tests that $\mathrm{P}$ cytotype is not maintained in the absence of chromosomal P factors. Genetics 115, 121-127.

Thompson, J. N. Jr., Woodruff, R. C. and Schaefer, G. B. (1978) An assay of somatic recombination in male recombination lines of Drosophila melanogaster. Genetica 49, 77-80.

Todo, T., Sakoyama, Y., Chigusa, S. I., Fukunaga, A., Honjo T. and Kondo, S. (1984) Polymorphism in distribution and structure of $\mathrm{P}$ elements in natural populations of Drosophila melanogaster in and around Japan. Jpn. J. Genet. 59, 441-451.

Yamamoto, A. H., Hihara, F. and Watanabe, T. K. (1984) Hybrid dysgenesis in Drosophila melanogaster: Predominance of $\mathrm{Q}$ factor in Japanese populations and its change in the laboratory. Genetica 63, 71-77. 